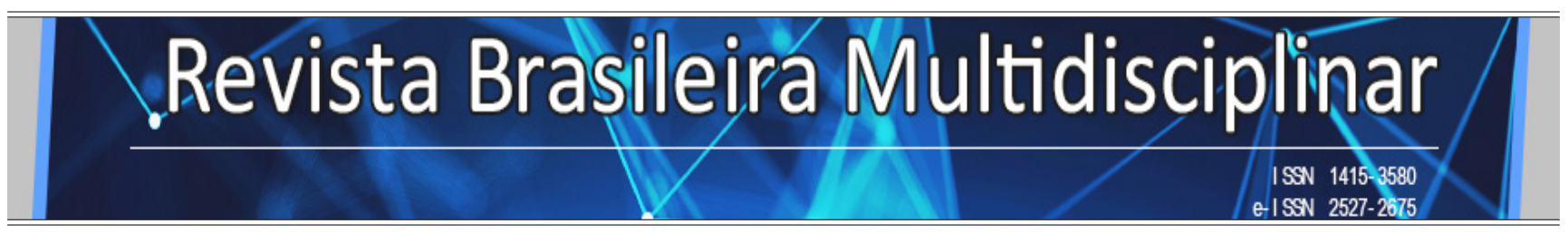

http://revistarebram.com/index.php/revistauniara

\title{
Análise parasitológica de hortaliças e AVAliação dos Cuidados e conhecimentos para o consumo in NATURA PEla população
}

\author{
Roberta Silva dos Reis*; Mariana Flores de Castro*; Geórgia Muccillo Dexheimer** \\ ${ }^{*}$ Universidade do Vale Do Taquari - UNIVATES. Lajeado, RS, Brasil. \\ ${ }^{*}$ Doutora em Biotecnologia. Docente da Universidade do Vale Do Taquari - UNIVATES. Lajeado, RS, Brasil.
}

${ }^{*}$ Autor para correspondência e-mail: gdexheimer@univates.br

\section{Palavras-chave}

Parasitoses intestinais

Hortaliças

Contaminação

Higienização

\section{KEYWORDS}

Intestinal parasites

Vegetables

Contamination

Sanitation

\section{RESUMO}

Introdução: o grande número de contaminações por enteroparasitos são indicativos da baixa qualidade higiênico-sanitária, e chamam a atenção para a importância de medidas voltadas à informação da população. Sabe-se que a contaminação de alimentos, em especial os consumidos in natura, é frequente e necessita de atenção no momento do consumo. Objetivo: avaliar a presença de parasitos intestinais presentes em amostras de hortaliças cultivadas em diferentes sistemas e verificar os cuidados prestados pela população para o consumo de tais alimentos. Métodos: Análise Por sedimentação espontânea e questionário para avaliação dos conhecimentos e hábitos de higienização de hortaliças. Resultados: foram analisadas 50 hortaliças hidropônicas, orgânicas e convencionais, dentre espécies de Agrião, Alface, Couve e Rúcula. Destas, 34 (68\%) apresentaram contaminação por parasitos intestinais, sendo a maior frequência de contaminação hidropônica, com positividade em 73,7\%. Os parasitos mais frequentes encontrados foram o Strongyloides stercoralis, Ancylostoma sp. e Entamoeba coli. Ainda, a população em geral não tem o hábito de higienizar as hortaliças de forma a eliminar possíveis patógenos. Conclusão: A correta higienização das hortaliças é um fator importante para o controle das parasitoses. É importante que haja vigilância e controle de qualidade da água e aditivos adicionados durante o plantio de hortaliças.

\begin{abstract}
Parasitological analysis of Vegetables and ASSESSMENT OF CARE AND KNOWLedge FOR FRESH CONSUMPTION BY POPULATION

Introduction: The large number of enteroparasite contamination is indicative of the poor hygienic-sanitary quality, and draw attention to the importance of measures aimed at informing the population. Contamination of food, especially those consumed in natura, is known to be frequent and needs attention at the time of consumption. Objective: to evaluate the presence of intestinal parasites present in samples of vegetables grown in different systems and to verify the care provided by the population for the consumption of such foods. Methods: Analysis by spontaneous sedimentation and questionnaire to evaluate the knowledge and habits of hygiene of vegetables. Results: 50 organic, conventional and hydroponic vegetables were analyzed, among species of Watercress, Lettuce, Cabbage and Arugula. Of these, 34 (68\%) presented intestinal parasite contamination, being the highest frequency of hydroponic contamination, with positivity in $73.7 \%$. The most frequent parasites were Strongyloides stercoralis, Ancylostoma sp. and Entamoeba coli. Also, the general population does not have the habit of sanitizing the vegetables in order to eliminate possible pathogens. Conclusion: The correct hygiene of vegetables is an important factor for the control of parasitoses. It is important to control and monitor the water quality and of the added additives during planting of vegetables.
\end{abstract}




\section{INTRODUÇÃo}

Com o aumento dos índices de Doenças Transmitidas por Alimentos (DTA), a segurança alimentar vem sendo cada vez mais rigorosa e importante. Entre as DTA destacam-se as enteroparasitoses, transmitidas através da ingestão de alimentos contaminados por estruturas parasitarias, estas, representam um grave problema de saúde pública, devido às várias manifestações clínicas que produzem na pessoa contaminada (BRAUER et al., 2016). O consumo de hortaliças é extremamente importante na dieta diária, com grande teor nutricional, fibras alimentares, vitaminas, sais minerais e ação antioxidante, ela também contribui para o funcionamento adequado do organismo, sendo assim, indispensável em uma alimentação correta (GREGÓRIO et al., 2012).

Sobre os meios de cultivos de hortaliças, conhecemos três: sistema convencional, orgânico e hidropônico. No sistema convencional, as hortaliças são cultivadas no solo com uso de fertilizantes químicos e pesticidas. No sistema orgânico, o cultivo também é realizado em solo, porém, sem a adição de fertilizantes químicos, pesticidas, ou qualquer produto químico, sendo utilizado apenas adubo orgânico. No sistema hidropônico, as hortaliças são cultivadas em tubos de plástico onde são adicionados fertilizantes químicos e uma solução dissolvida de nutrientes (SANTOS et al., 2016).

A principal forma de contaminação desses alimentos ocorre principalmente quando irrigado com água contaminada contendo formas infectantes de parasitos presentes em material fecal de origem humana ou de outros animais, como cães e gatos (JUNG et al., 2014). Portanto, a correta higienização destes alimentos torna-se essencial para a prevenção de doenças parasitárias. Além disso, outra forma de contaminação destes alimentos se dá através da sua manipulação, tornando-se importante a higienização correta das mãos para que não ocorra contaminação durante o seu manuseio (BOAVENTURA et al., 2017).

Comumente, a população utiliza apenas água, ou água e ácido acético (vinagre) para a higienização das hortaliças. Porém, sabe-se que estes produtos não apresentam 100\% de eficiência na eliminação de parasitos intestinais. Para isto, deve-se utilizar água sanitária a 1\% para que os parasitos possam ser eliminados na sua totalidade (NASCIMENTO; ALENCAR, 2014). Diante do exposto, torna-se importante a investigação de contaminação parasitária em produtos consumidos in natura, bem como a avaliação do conhecimento e práticas realizadas pela população para o consumo das hortaliças para que possam ser desenvolvidas medidas que busquem minimizar os riscos para o desenvolvimento de parasitoses.

\section{Procedimentos Metodológicos}

Tratou-se de um estudo qualitativo e quantitativo, onde foram analisadas hortaliças de diversos estabelecimentos comerciais no Vale do Taquari, no interior do Rio Grande do Sul, observando-se a prevalência de contaminação parasitológica de cada uma delas.

Foram analisadas amostras de alface (Lactuca sativa), rúcula (Eruca sativa), couve (Brassica oleracea) e agrião (Nasturtium officinale) coletados em diferentes locais de venda como em mercados e feiras orgânicas no período de julho e agosto de 2018 e janeiro a março de 2019. As amostras foram obtidas em períodos de frio e calor, buscando diferentes formas de cultivo (convencional, orgânico e hidropônico) conforme indicação do local de venda e/ou produtor. Os pesquisadores comprometeram-se a não divulgar os nomes das marcas e/ou produtores das hortaliças analisadas.

A metodologia da análise parasitológica das hortaliças foi baseada em método previamente descrito (GREGÓRIO et al., 2012; TAKAYANAGUI et al., 2007). Para a análise parasitológica, cada hortaliça foi colocada em saco plástico com $250 \mathrm{ml}$ de água destilada e agitada manualmente por 30 segundos. Após, cada hortaliça foi desfolhada e colocada em um recipiente de vidro contendo $250 \mathrm{ml}$ de água destilada. Cada folha foi lavada com o auxílio de uma escova de cerdas macias. Os líquidos da primeira e segunda lavagem foram filtrados em gaze sob um cálice de sedimentação e deixados em repouso durante 24 ho- 
ras. Após o período de sedimentação, foram preparadas lâminas em duplicata para cada amostra para análise microscópica. As lâminas foram analisadas em aumento de 40x.

Durante o período de análises, a população em geral foi convidada a participar do estudo, respondendo um questionário sobre os conhecimentos e hábitos de consumo e higiene das hortaliças. Após a leitura das lâminas, os resultados foram tabulados no Software Microsoft Excel para a geração de gráficos e tabelas para a apresentação dos resultados.

\section{RESUlTADOS}

Durante o período de verão (calor), nos meses de janeiro a março, foram analisadas 26 amostras de hortaliças, dentre hidropônicas (11), orgânicas (4) e convencionais (11), com espécies de Alface (Lactuca sativa), Agrião (Nasturtium officinale), Couve (Brassica oleracea) e Rúcula (Eruca sativa). Do total de amostras, 15 (57,69\%) apresentaram algum tipo de contaminação por parasitos. As hortaliças com maior taxa de contaminação foram a Rúcula, com 100\% de contaminação e Agrião, com $80 \%$ de contaminação das amostras. Além disso, o meio orgânico foi o único que não apresentou contaminação no período de calor, sendo que o meio convencional apresentou 72,72\% de contaminação e o meio hidropônico 63,63\%.

Durante o período de frio, nos meses de julho e agosto, foram analisadas 24 amostras de hortaliças, dentre hidropônicas (8), orgânicas (8) e convencionais (8), com espécies de Alface, Agrião, Couve e Rúcula. Do total de amostras no período de frio, 19 (79,2\%) apresentaram algum tipo de contaminação por parasitos. As hortaliças com maior taxa de contaminação foram a Alface, com $91 \%$ e a Rúcula com $100 \%$. Ainda, os meios de cultivo hidropônico e orgânico foram os que mais apresentaram percentual de contaminação parasitária, com $87,5 \%$ das amostras positivas em ambos.

Assim, a análise final foi constituída por 50 amostras de hortaliças, 19 convencionais, 19 hidropônicas e 12 orgânicas. Destas, 34 (68\%) apresentaram algum tipo de contaminação parasitária. O meio com maior percentual de contaminação foi o hidropônico, com 73,7\% (Tabela 1).

O parasito intestinal mais encontrado nas amostras positivas foi o Strongyloides stercoralis, presente em 29 (85,3\%) amostras das 34 positivas (Gráfico 1)

Durante o estudo, foi aplicado um questionário através da plataforma do GoogleForms ${ }^{\varpi}$ onde a população foi convidada a responder perguntas acerca do consumo, lavagem e conhecimento sobre as hortaliças. O questionário foi disponibilizado em redes sociais com o intuito de verificar o conhecimento acerca da lavagem de hortaliças, não levando em consideração o fator socioeconômico. Foram obtidas 229 respostas do questionário, sendo que 228 (99,6\%) afirmaram consumir hortaliças durante a semana. Destes, $39(17,1 \%)$ afirmaram consumir todos os dias, $114(50 \%)$ entre duas a quatro vezes por semana e 75 (32,9\%) uma vez por semana. A população também foi questionada quanto ao tipo de cultivo das hortaliças consumidas, sendo que 80 (35\%) pessoas afirmaram consumir hortaliças de cultivo convencional, 57 (25\%) orgânica, 18 (8\%) hidropônica e 73 (32\%) afirmaram não saber ou não ter preferência quanto a esta característica.

Sobre o hábito de lavagem das hortaliças, $227(99,1 \%)$ das pessoas responderam que lavam as folhas antes do consumo, sendo que a maioria afirmou utilizar apenas água para a lavagem (Gráfico 2).

Ao final do questionário, os respondentes foram questionados sobre o conhecimento sobre a transmissão de doenças através do consumo de frutas ou verduras mal lavadas, sendo que 7 (3,1\%) afirmaram não ter conhecimento deste fato. 
Tabela 1 - Hortaliças analisadas e contaminadas conforme meio de cultivo e temperatura.

\begin{tabular}{|c|c|c|c|c|c|}
\hline & Agrião & Alface & Couve & Rúcula & Total \\
\hline & \multicolumn{5}{|c|}{ Total analisado/total contaminado (\% contaminado total sazonal) } \\
\hline \multicolumn{6}{|l|}{ Convencional } \\
\hline Calor & $2 / 2$ & $3 / 1$ & $3 / 2$ & $3 / 3$ & $11 / 8(72,7 \%)$ \\
\hline Frio & $2 / 2$ & $2 / 1$ & $2 / 0$ & $2 / 2$ & $8 / 5(62,5 \%)$ \\
\hline Total analisado & 4 & 5 & 5 & 5 & 19 \\
\hline Total contaminado & $4(100 \%)$ & $2(40 \%)$ & $2(40 \%)$ & $5(100 \%)$ & $13(68,4 \%)$ \\
\hline \multicolumn{6}{|l|}{ Hidropônica } \\
\hline Calor & $3 / 2$ & $5 / 2$ & - & $3 / 3$ & $11 / 7(63,6 \%)$ \\
\hline Frio & $1 / 0$ & $4 / 4$ & - & $3 / 3$ & $8 / 7(87,5 \%)$ \\
\hline Total analisado & 4 & 9 & - & 6 & 19 \\
\hline Total contaminado & $2(50 \%)$ & $6(66,7 \%)$ & - & $6(100 \%)$ & $14(73,7 \%)$ \\
\hline \multicolumn{6}{|l|}{ Orgânica } \\
\hline Calor & - & $4 / 0$ & - & - & $4 / 0(0 \%)$ \\
\hline Frio & - & $5 / 5$ & $3 / 2$ & - & $8 / 7(87,5 \%)$ \\
\hline Total analisado & - & 9 & 3 & - & 12 \\
\hline Total contaminado & - & 5 & 2 & - & $7(58,3 \%)$ \\
\hline Total analisado & $8(100 \%)$ & $23(100 \%)$ & $8(100 \%)$ & $11(100 \%)$ & $50(100 \%)$ \\
\hline Total contaminado & $6(75 \%)$ & $13(56,5 \%)$ & $4(50 \%)$ & $11(100 \%)$ & $34(68 \%)$ \\
\hline
\end{tabular}

Fonte: Elaborado pelas autoras.

Gráfico 1 - Percentual de cada espécie de parasito intestinal observada nas hortaliças contaminadas ( $\mathrm{n}=34)$.

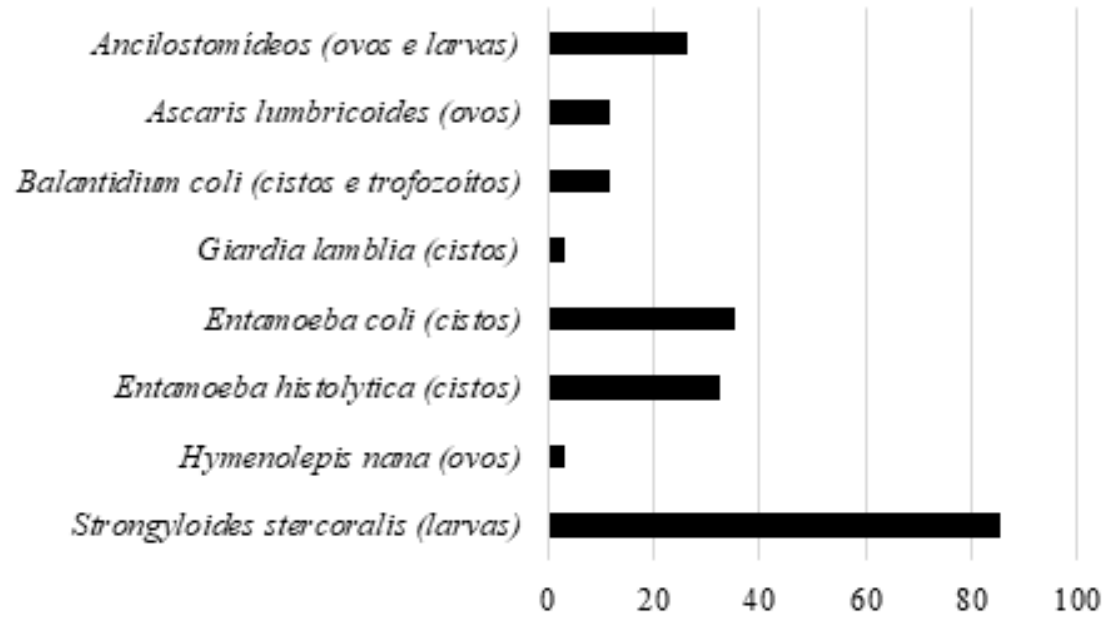

Fonte: Elaborado pelas autoras. 
Gráfico 2 - Uso de produtos para a lavagem de hortaliças pela população respondente.

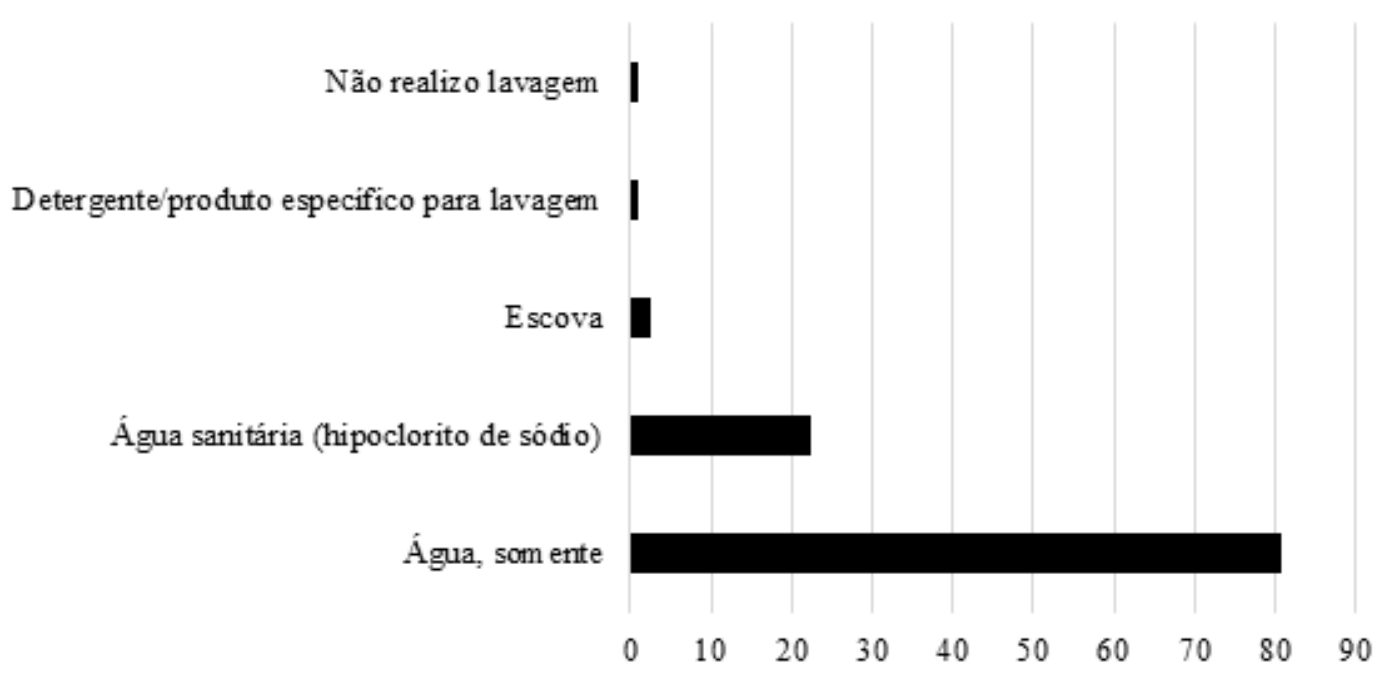

Fonte: Elaborado pelas autoras.

\section{Discussão}

O parasito com maior incidência encontrado nas hortaliças analisadas foi o Strongyloides stercoralis, presente em 29 amostras das 34 positivas. A presença deste parasito é um indicador da falta de saneamento básico, hábitos culturais, e educação sanitária da população, que fica suscetível a fontes de contaminação pelas larvas desse parasito (VIEIRA; GOMES, 2017). Existem muitos estudos que relatam a presença de parasitos intestinais em amostras de hortaliças. Em Santa Catarina, um estudo encontrou Strongyloides stercoralis em 100\% das amostras analisadas, seguido por 66\% de Entamoeba coli, e 33\% de ancilostomídeos, Entamoeba histolytica e Trichuris trichiuria (JUNG et al., 2014).

Em Londrina no Paraná um estudo analisou 16 amostras de alface e almeirão, havendo predominância de cistos de Endolimax nana em 100\% das amostras, seguidos de 87,5\% de larvas de Ancilostomídeos, 87,5\% de cistos de Balantidium coli, Entamoeba histolytica, 75\% de larvas de Strongyloides stercoralis e 62,5\% de Entamoeba coli nas alfaces e 50\% nos almeirões (NOMURA et al., 2015). No município de São Mateus, Espirito Santo, 86,85\% das amostras analisadas estavam contaminadas com algum tipo de parasito (BRAUER et al., 2016). Um estudo feito em São Paulo, analisou 20 amostras de alface de dois municípios diferentes, destas, apenas 3 estavam negativas para a presença de algum parasita intestinal, enquanto as outras 17 estavam contaminadas em sua maioria com Endolimax nana, seguido de Entamoeba Coli, Entamoeba histolytica, Strongyloides stercoralis, Giardia lamblia e Enterobius vermicularis(SARAIVA et al., 2005).

Contaminação parasitológica de hortaliças também foi observada em estudo realizado em Bangladesh, onde foram avaliadas 200 amostras, incluindo cenoura, pimenta verde, tomate, entre outros. Destas, 123 (61,5\%) estavam contaminadas com diferentes espécies de parasitos. Ovos de Ascaris lumbricoides foram os mais freqüentes, com 36,5\%, seguido de Strongyloides stercoralis com 35,5\%, Entamoeba histolytica com 8,5\%, Enterobius vermicularis 3,5\%, Trichuris trichiura 1,5\% e Giardia lamblia 1,0\% (AZIM et al., 2018). A ciclosporíase, uma infecção causada pelo protozoário Cyclospora cayetanensis através de água e alimentos contaminados também foi associada com mistos de saladas prontas para o consumo no Iowa e Nebraska, Estados Unidos da América (BUSS et al., 2016). Outro agente transmitido por água e alimentos contaminados de maneira global é o Toxoplasma gondii, causador da Toxoplasmose. Este vem sendo associado com o consumo de frutas e verduras mal lavadas e foi reportada sua contaminação em 
saladas prontas para consumo na Europa (LALLE et al., 2018).

No presente estudo as amostras de agrião e rúcula apresentaram maior índice de contaminação, com $75 \%$ e 100\% respectivamente. Em relação aos cultivos, as amostras hidropônicas apresentaram maior taxa de contaminação com $73,7 \%$. A comparação dos meios de cultivo também foi realizada em Teresina no Piauí. Foram analisadas 15 amostras de alface provenientes de quatro redes de supermercados. Destas, cinco amostras eram alfaces convencionais americanas, cinco alfaces convencionais crespas e cinco alfaces hidropônicas americanas. Não foi observada diferença significativa de contaminação entre os cultivos, porém, verificou-se uma elevada incidência de contaminantes microbiológicos e parasitológicos (BARBOSA et al., 2016).

Muitos fatores podem estar relacionados com a contaminação de hortaliças, como a qualidade da água, condições climáticas e higiênico-sanitárias, até o transporte para comercialização dessas hortaliças e as condições higiênicas dos manipuladores (MARTINS et al., 2018). Outro estudo também comparou os meios de cultivos, do total de 180 amostras analisadas, 71 (39,4\%) apresentaram contaminação por pelo menos um parasito, sendo essas 34 (18,9\%) de alfaces cultivadas em meio hidropônico, 20 (11,1\%) sistema orgânico, e 17 (9,4\%) sistema convencional (SANTOS, 2016).

$\mathrm{Na}$ comparação da sazonalidade, no período de frio observou-se $19(79,2 \%)$ das amostras com algum tipo de contaminação por parasitos intestinais, enquanto no calor foram 15 (57,7\%) amostras contaminadas. A maior taxa de contaminação foi de alface e rúcula no período de frio e agrião e rúcula no período de calor. Além disso, os meios de cultivo hidropônico e orgânico foram os que mais apresentaram percentual de contaminação parasitária no frio e hidropônico e convencional no período de calor. Em ambos os períodos, o parasito mais frequente foi o Strongyloides stercoralis. A contaminação por parasitos também pode ser influenciada por períodos de chuva. Um estudo realizou duas coletas em períodos diferentes em 3 regiões distintas de Santa Catarina. Na primeira coleta, 100\% das amostras apresentaram contaminação por parasitos, sendo que a larva de Strongyloides stercoralis estava presente em todas as hortaliças analisadas e cistos de Entamoeba coli estavam presentes em 66\%, ovos de ancilostomídeos e cistos de Entamoeba histolytica em $33 \%$. Já na segunda coleta, houve diminuição da contaminação, com presença de Trichuris sp., cistos de Entamoeba coli e larvas de Strogyloides stercoralis em 33\% das amostras analisadas (SOUZA et al.,2000).

Além disso, os parasitos no solo têm sua sobrevivência controlada não somente por disponibilidade de alimento, mas também pelas condições climáticas. Larvas de nematódeos podem sobreviver por períodos de 42 a 126 dias na primavera e outono, dependendo muito das condições climáticas. Vale salientar que o desenvolvimento e a sobrevivência de parasitos no solo são critérios importantes para a contaminação e transmissão destes organismos. Larvas de Strongyloides stercoralis podem viver indefinidamente no solo sob forma de vida livre. São condições ideais as temperaturas quentes, entre 25 e $30{ }^{\circ} \mathrm{C}$ e locais úmidos, porém, a luz ultravioleta pode apresentar ação deletéria para as larvas (VAN DIJK et al., 2009).

O presente trabalho também contou com a participação da população quanto ao consumo e higienização das hortaliças através de um questionário, onde se pode observar que $227(99,1 \%)$ das pessoas responderam que lavam as folhas antes do consumo, sendo que a maioria respondeu utilizar apenas água para a lavagem. Este fato deve ser avaliado com cuidado, já que no presente estudo foram realizadas duas lavagens para cada hortaliça, sendo estas apenas com água. A primeira lavagem foi um enxágue e a segunda lavagem com escovação, e não foram observadas diferenças ou diminuição da contaminação em virtude da primeira lavagem. Sendo assim, pode-se perceber que a simples lavagem de enxágue com água não diminui os riscos de contaminação das hortaliças por parasitos intestinais.

Um estudo feito em Garanhus - PE, analisou o perfil do consumidor na higienização das hortaliças em feiras livres e supermercados, $28 \%$ e $34 \%$ respectivamente disseram utilizar algum produto a base de cloro como sanitizante (LINO et al., 2009). Outro estudo avaliou o conhecimento da população a respeito da 
higienização das hortaliças, a contaminação parasitológica e a lavagem com os mesmos sanitizantes. Foi observado que $38 \%$ dos entrevistados conheciam algum tipo de doença transmitida por hortaliças mal higienizadas enquanto $62 \%$ desconhecia esta informação. Ainda, o método mais comum de lavagem era somente a água. Foi encontrada uma prevalência de 91,6\% de contaminação parasitológica das amostras analisadas, sendo que o sanitizante mais eficaz para qualquer tipo de adubação (100\%) foi a água sanitária. Comumente a população utiliza hipoclorito de sódio ou ácido acético para a higienização de hortaliças (GOMES et al., 2011). Um estudo avaliou a contaminação parasitológica de hortaliças e a eficiência destes reagentes na lavagem. Foram analisadas 24 amostras, sendo que 41,7\% apresentavam contaminação parasitária. Além disso, o uso do hipoclorito de sódio a 1\% mostrou-se mais eficaz na higienização de amostras contaminadas por parasitos do que o ácido acético (DO NASCIMENTO; ALENCAR, 2014).

\section{ConCluSÃo}

A correta higienização das hortaliças é um fator importante para o controle das parasitoses. Para que este fato ocorra, é necessária a disseminação do conhecimento de técnicas adequadas para a eliminação de patógenos em alimentos consumidos in natura. Uma vez que não houve um tipo de cultivo de hortaliça totalmente sem a presença de parasitos, deve-se ressaltar a vigilância e controle de qualidade da água e aditivos adicionados durante o plantio de hortaliças que podem contribuir para a elevação da taxa de contaminação desses alimentos. Orienta-se a lavagem com hipoclorito de sódio a 1\% seguindo as instruções no rótulo dos produtos próprios para esta finalidade para diminuir as chances de contaminação.

As hortaliças avaliadas neste estudo foram classificadas conforme o meio de cultivo indicado na embalagem. Salienta-se que alguns produtos comercializados não apresentavam indicações de meio de cultivo, não podendo ser incluídas no estudo. Este dado é importante já que o consumidor deve saber e poder escolher o produto conforme o seu cultivo, tendo em vista que produtos orgânicos vêm ganhando força no mercado alimentício.

\section{REFERÊNCIAS}

AZIM, A.; AHMED, S.; PAUL, S.K.; NASREEN, A.S.; SARKAR, SR; AHMED, U.M.; NAJNIN, A.; HOSSAIN, M.A. Prevalence of Intestinal Parasites in Raw Vegetables Consumed by Inhabitants of Mymensingh City. Mymensingh medical journal: MMJ, v. 27, n. 3, p. 440-444, 2018.

BOAVENTURA, L.T.A; FRADE, L.P.; WEBER, M.L.; PINTO, B.O.S. Conhecimento de manipuladores de alimentos sobre higiene pessoal e boas práticas na produção de alimentos. Revista Univap, v. 23 , n. 43, p. 53-62, 2017.

BARBOSA, V.A.A.; FILHO, F.C.C.; SILVA, A.X.L; OLIVEIRA, D.G.S; ALBUQUERQUE, W.F; BARROS, V.C. Comparação da contaminação de alface (Lactuca sativa) proveniente de dois tipos de cultivo. Revista Brasileira de Higiene e Sanidade Animal, v. 10, n. 2, p. 231-242, 2016.

BRAUER, A.M.N.W.; SILVA, J.C.S; SOUZA, M.A.A. Distribuição de enteroparasitos em verduras do comércio alimentício do município de São Mateus, Espírito Santo, Brasil. Natureza Online, v. 14, n. 1, p. $055-60,2016$.

BUSS, B.F.; JOSHI, M.V.; O’KEEFE, A.L.; ALLENSWORTH, C.D. Regional investigation of a cyclosporiasis outbreak linked to imported romaine lettuce-Nebraska and Iowa, June-August 2013. Epidemiology \& 
Infection, v. 144, n. 9, p. 1807-1817, 2016.

GOMES, C.U.S.; MACHADO, E.J.; MÜCKE, N. Avaliação das metodologias de higienização de hortaliças in natura empregadas pela população de Medianeira-Pr, utilizando alfaces (lactuca sativa) de diferentes fontes de adubação. 2011. 57 f. Trabalho de Conclusão de Curso. Universidade Tecnológica Federal do Paraná, Medianeira. 2011.

GREGÓRIO, D.S.; MORAES, G.F.A.; NASSIF, J.M.; ALVES, M.R.M.; CARMO, N.E.; JARROUGE, M.G. Estudo da contaminação por parasitas em hortaliças da região leste de São Paulo. Science in health, v. 3, n. 2, p. 96-103, 2012.

JUNG, GJ; BALDISSERA, LC; PIOVESAN, YA; PERETTI, G; LOUVATEL, K; PEGORARO, O; POPP, N; MULLHER, GA; WAGNER, G. Parasitos em alface Lactuca sativa (Asterales: Asteraceae) cultivadas em pequenas propriedades rurais dos municípios de Capinzal, Vargem Bonita e Lacerdópolis, Santa Catarina, Brasil. Unoesc \& Ciência, v. 5, n. 1, p. 103-108, 2014.

LALLE, M.; POSSENTI, A.; DUBEY, J.P.; POZIO, E. Loop-Mediated Isothermal Amplification-LateralFlow Dipstick (LAMP-LFD) to detect Toxoplasma gondii oocyst in ready-to-eat salad. Food microbiology, v. 70, p. 137-142, 2018.

LINO, T.F.L.; BEZERRA, J.E.G.; BRANDESPIM, D.F.; SANTOS, G.M. Perfil do consumidor na higienização de hortaliças adquiridas em feiras livres e nos supermercados do município de GaranhunsPE. Horticultura brasileira, v. 55292, p. 270, 2009.

MARTINS, A.G.; FERREIRA, A.C.S. Caracterização das condições higiênico-sanitária das feiras livres da cidade de Macapá e Santana-AP. Revista Arquivos Científicos (IMMES), v. 1, n. 1, p. 28-35, 2018.

NASCIMENTO, E.D.; ALENCAR, F.L.S. Eficiência antimicrobiana e antiparasitária de desinfetantes na higienização de hortaliças na cidade de Natal-RN. Ciência e Natura, v. 36, n. 2, p. 92-106, 2014.

NOMURA, P.R.; FERREIRA, A.R.M; RAFAELLI, R.A; AUGUSTO, J.G.; TATAKIHARA, V.L.H.; CUSTÓDIO, L.A.; MURAD, V.A. Estudo da incidência de parasitas intestinais em verduras comercializadas em feira livre e supermercado de Londrina. Semina: Ciências Biológicas e da Saúde, v. 36, n. 1Supl, p. 209-214, 2015.

SANTOS, J.S. Análise parasitológica em hortaliças cultivadas em diferentes sistemas de produção. 2016. 39 f. Dissertação (Mestrado em Ciências Agrárias) - Universidade do Oeste Paulista, Presidente Prudente, 2016.

SARAIVA, N.; BALLESTERO, L.G.B.; POVEA, A.M.; ANIBAL, F.F. Incidência da contaminação parasitária em alfaces nos municípios de Araraquara (SP) e São Carlos (SP). Revista Brasileira Multidisciplinar, v. 9, n. 1, p. 213-216, 2005.

SOUZA, P.; BELLATO, V.; SARTOR, A.A.; RAMOS, C.I. Período para desinfestação das pastagens por larvas de nematóides gastrintestinais de ovinos, em condições naturais nos campos de Lages, SC. Revista 
Reis et al.

Brasileira de Parasitologia Veterinária, v. 9, n. 2, p. 159-164, 2000.

TAKAYANAGUI, O.M.; CAPUANO, D.M.; OLIVEIRA, C.A.D.; BERGAMINI, A.M.M.; OKINO, M.H.T.; SILVA, A.A.M.C.C.; OLIVEIRA, M.A.; RIBEIRO, E.G.A.; TAKAYANAGUI, A.M.M. Avaliação da contaminação de hortas produtoras de verduras após a implantação do sistema de fiscalização em Ribeirão Preto. Rev. Soc. Bras. Med. Trop, p. 239-241, 2007.

VAN DIJK, J.; LOUW, M.D.E.; KALIS, L.P.A.; MORGAN E.R. Ultraviolet light increases mortality of nematode larvae and can explain patterns of larval availability at pasture. International journal for parasitology, v. 39, n. 10, p. 1151-1156, 2009.

VIEIRA, E.K. Influência das estações seca e cheia na ocorrência das parasitoses intestinais no município de Tefé. 2017. 9f. (Trabalho de Conclusão de Curso) Universidade do Estado do Amazonas, Tefé, 2017. 